\title{
STRESS ANALYSIS OF THE SRP REACTOR TANK
}

\author{
by
}

J. W. Walker

Pile Engineering Division

October 1955

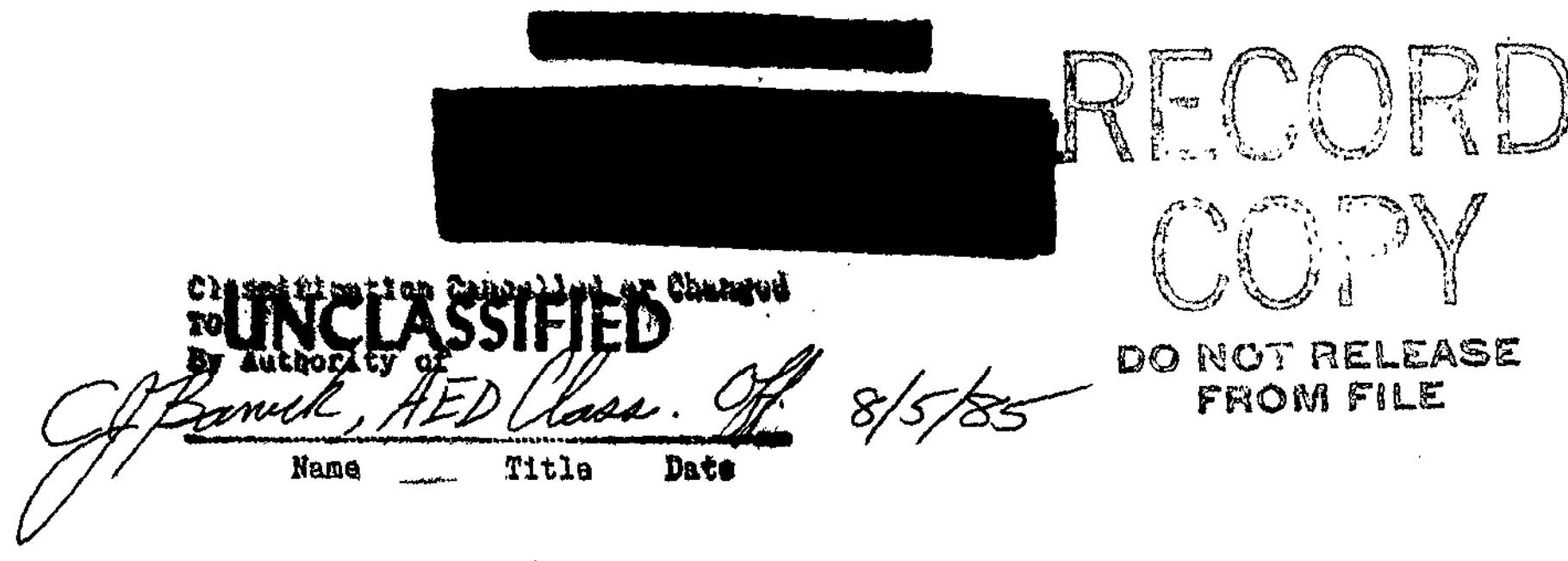

E. 1. du Pont de Nemours \& Co.

Explosives Department - Atomic Energy Division

Technical Division - Savannah River Laboratory 


\section{STRESS ANALYSIS OF THE SRP REACTOR TANK}

by

J. W. Walker

Pile. Engineering Division

October 1955
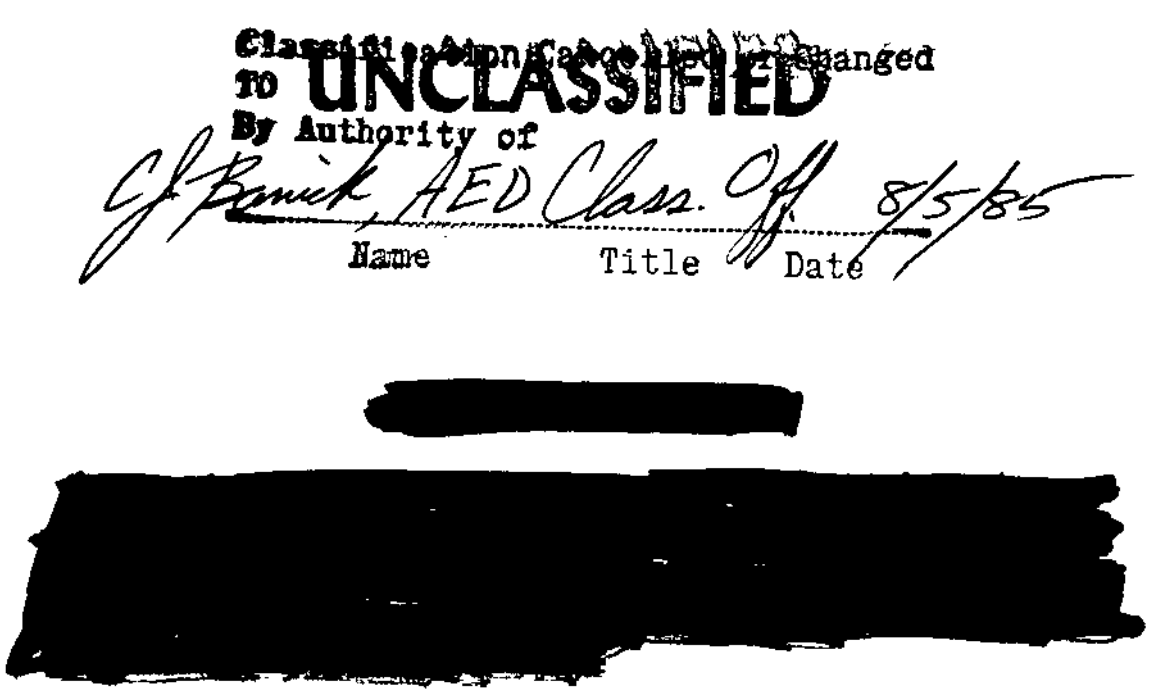

E. I. du Pont de Nemours \& Co.

Explosives Department - Atomic Energy Division Technical Division - Savannah River Laboratory

\section{Printed for}

The United States Atomic Energy Commission Contract AT $(07-2)-1$ 


\section{ABSTRACT}

Equations are derived for the discontinuity stress in a cylindrical tank that is mounted vertically on a header and is open at the top. The analysis includes a derivation of equations for the prediction of the deflection and slope of the header by relating the strain energy in bending a circular plate to the strain energy in bending the header. The stresses that result from pressure and temperature are included in the analysis.

External Distribution according to M-3679 (16th Ed.) 


\section{- TABLE OF CONTENTS}

LIST OF FIGURES AND TABLES

$\underline{\text { Page }}$

INTTRODUCTION

SUMMARY

DISCUSSION

Deflection of the Bottom Shield

Derivation of the Equations for Pressure Deflection

Strain Energy in Bending a Circular Plate

Verification of Derivation - Strain Energy in a Plate

Strain Energy in Bending the Tubes

Total Strain Energy of the Header

Derivation of the Equation for the Thermal Deflection

Total Deflection

Sample Calculation of Header Deflection

Calculation of Plate Energy

Calculation of Tube Energy

Calculation of Thermal Deflection

Reactor Tank Stress

Moments and Forces at the "T" Joint

18

Derivation of Moments and Forces at the "T" Joint

Deflection at the "T" Joint

Slope at the "T" Joint

Moment at the "T" Joint

20

21

Sample calculation of Stress at the "T" Joint

NOMENCLATURE 


\section{LIST OF FIGURES AND TABLES .}

Figure

Page

1 Structure of Savannah River Reactor 28

2 Deflection of the Bottom Shield 29

3 Bending Stress in the Tank Wall at "A" 30

Table

1 Solution of Equation 13 
INTRODUCTION

Thermal gradients and hydraulic loads distort the bottom shield and main tank of a reactor at the Savannah River Plant. Because the stresses that result from these loads cannot be measured directly, computational methods are necessary to determine the stresses from measurable deflections and temperatures. Radiation shielding, flow control, and other reactor design considerations require unusual shapes and supports for which the analyses of deflections and stresses are complex. This report presents an analytical method for computing the deflection of the bottom shield and for relating the deflection to the discontinuity stress at the "T" joint between the shield and the reactor tank.

\section{SUMMARY}

An analysis developed for prediction of the deflection of the bottom shield of a Savannah River reactor relates the strain energy in bending of unrestrained circular plates to that in bending of circular plates reinforced by tubes. The resulting equations are applicable to the computation of the deflection of similar structures.

It is estimated that the bottom shield deflects downward 0.0017 inch for each pound per square inch of effective pressure on the shield. This deflection is in good agreement with the measurements of the actual deflection due to pressure.

The bottom shield also deflects as a result of unequal temperatures of the top and bottom tube sheets. This upward deflection is estimated as $0.0022 \Delta \mathrm{T}$ inch, when the top tube sheet is hotter than the bottom tube sheet by an amount $\Delta \mathrm{T}^{\circ} \mathrm{C}$.

The bending stress in the reactor tank was related to (I) the deflection of the bottom shield to which the tank is attached, (2) the difference in temperature between the tank and the shield, and (3) the pressure within the tank. The dependence of the stress upon the pertinent temperature differences and pressures is summarized in the following table:

\section{BENDING STRESS AT THE "T" JOINT}

\section{Source of Bending Stress}

Top tube sheet of shield hotter than tank wall at the " $\mathrm{T}$ " joint

Top tube sheet of shield hotter than bottom tube sheet

Static pressure in bottom of the tank

Mean effective pressure on bottom shield including dynamic thrust of the coolant flow

$$
\begin{gathered}
\frac{\text { Coefficient of Stress }}{735 \mathrm{lb} / \mathrm{in}^{2} \cdot /{ }^{\circ} \mathrm{C}} \\
101 \mathrm{lb} / \mathrm{in}^{2} \cdot /{ }^{\circ} \mathrm{C} \\
348 \mathrm{lb} / \mathrm{in}^{2} \cdot \mathrm{psi} \\
79 \mathrm{lb} / \mathrm{in}^{2} \cdot \mathrm{psi}
\end{gathered}
$$




\section{DISCUSSION}

DEFLECTION OF THE BOTTOM SHIELD

The bottom shield of a Savannah River reactor is essentially a header. It is composed of two circular plates joined by approximately 700 tubes that are three inches in diameter. Figure 1 shows the location of the bottom shield with respect to other reactor components. The dimensions and the features of construction that are important in the deflection analysis are shown in the accompanying diagram.

Downward deflection of the shield results from the pressure (q). of the water in the reactor and from the weight of the supported members. An upward component of deflection of the shield occurs because the temperature of the top tube sheet (B) (see figure below) is greater than the temperature of the bottom tube sheet (c) during reactor operation. The total shield deflection is obtained by superposing the thermal deflection on the pressure deflection.

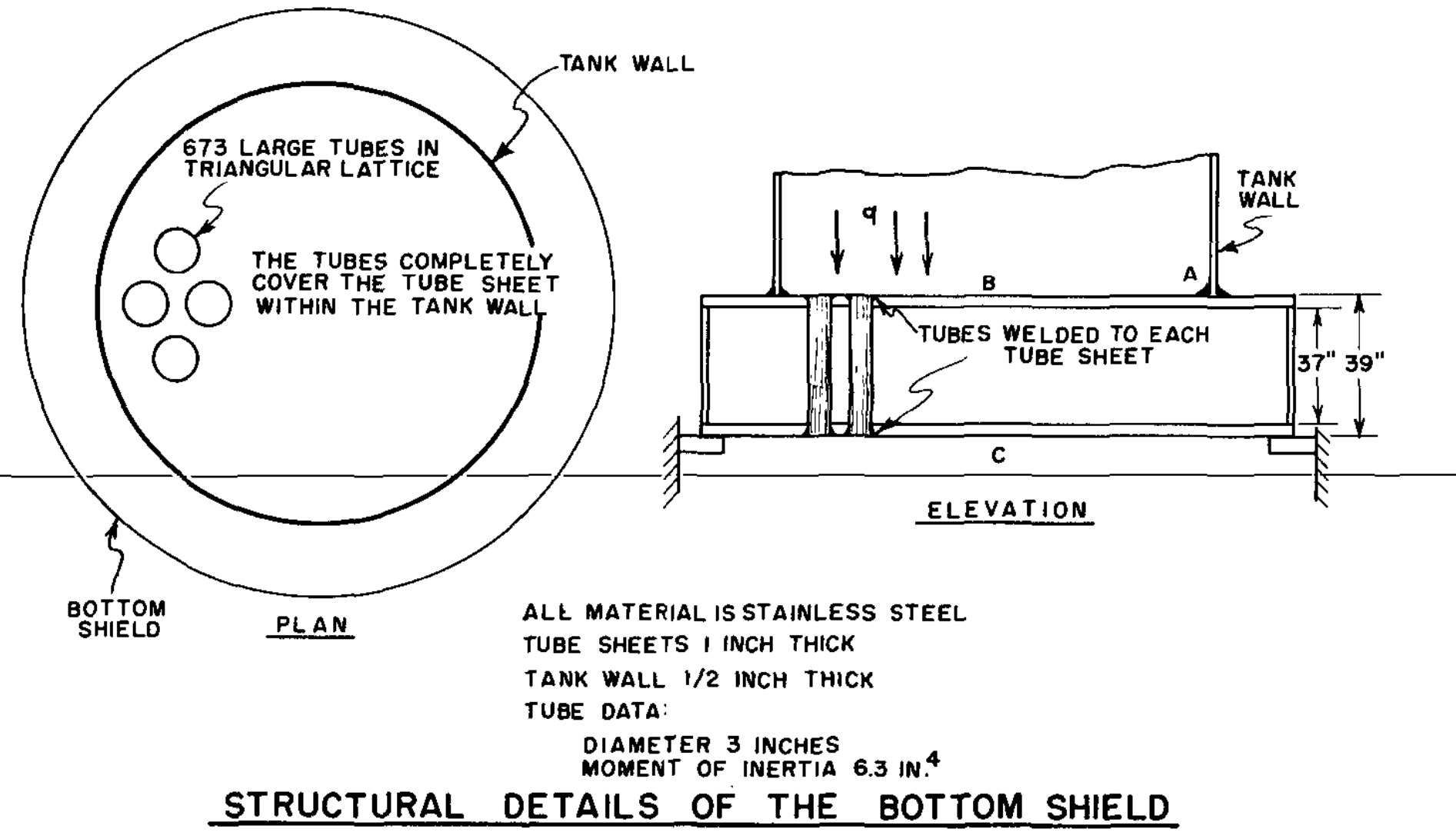

A knowledge of the magnitude of the bottom shield deflection is important in the analysis of stresses in a Savannah River reactor, since the deflection causes rotation and consequent bending stresses at location (A) in the tank wall. 
Consider a header, such as the bottom shield of the reactor, loaded uniformly and supported at its edge. The following figure illustrates the structure considered in this analysis.

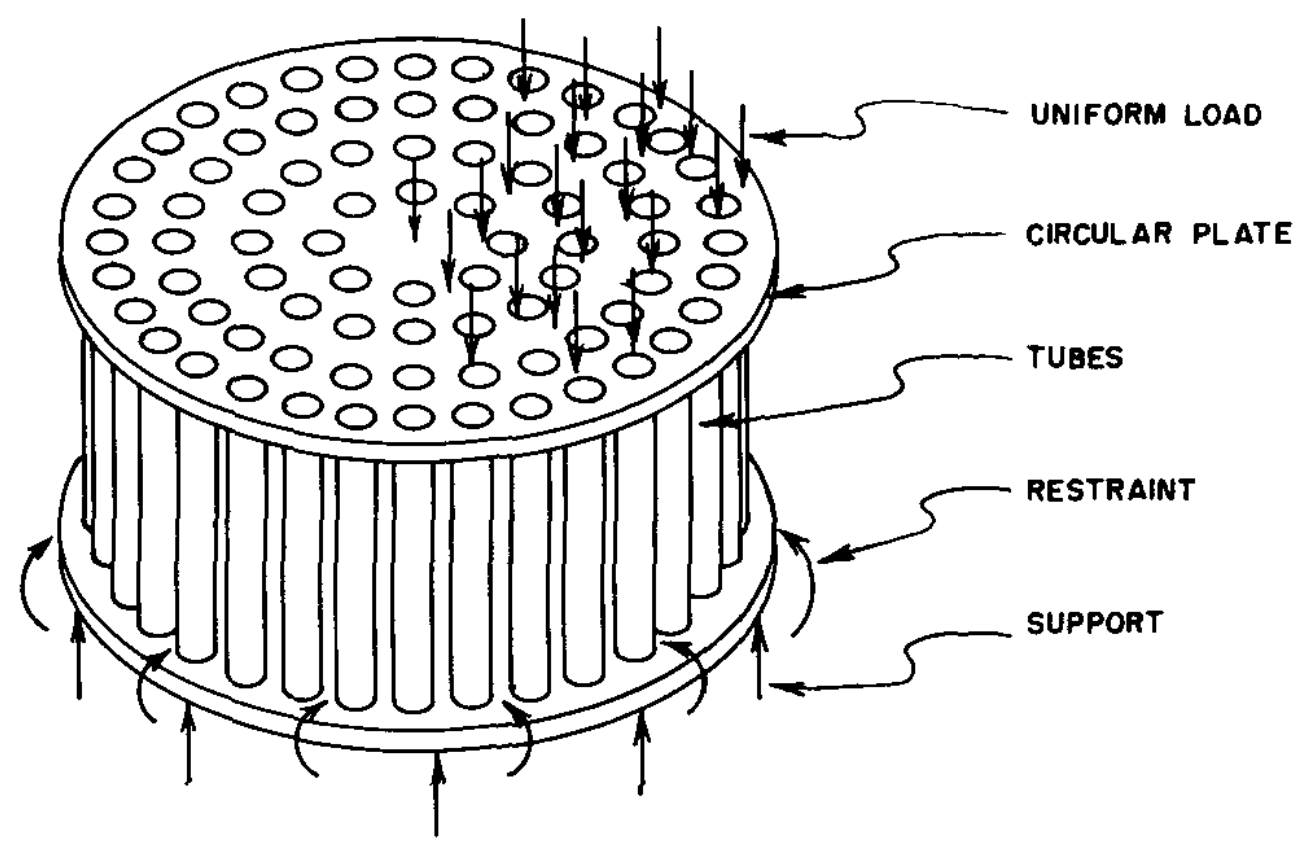

The header is assumed to be initially flat. The application of a load deflects the header downward until the upward restraining force equals the downward force. Under such a condition of stability, the change in potential energy of the load must equal the strain energy stored in the system. The deflection equation of the composite structure (two plates and $\mathrm{N}$ tubes) may be derived by application of this basic concept of the conservation of energy.

\section{Strain Energy in Bending a Clrcular Plate}

The total strain energy in the header is the sum of the energy in each part. For the particular header under consideration the energy is contained in the plates and in the tubes. The following symbols are employed in deriving the various expressions for the energy of strain:
a
Outside radius of plate, inches
$D=\frac{E h^{3}}{12\left(1-\mu^{2}\right)}$ Flexural rigidity, in. $-1 b$
$\mathrm{D}_{0}$
E
Effective flexural rigidity of the header Young's modulus, $1 \mathrm{~b} / \mathrm{in}$.
$\mathrm{h}$ Plate thickness, inches
$\mathrm{L}$
Length of tube, inches 


\begin{tabular}{|c|c|}
\hline M & Bending moment, lb-in. \\
\hline$M_{r}$ & Specific radial bending moment, $1 \mathrm{~b}$-in./1n. \\
\hline $\mathrm{M}_{\mathrm{t}}$ & Specific tangential bending moment, lb-in./in. \\
\hline $\mathrm{P}$ & Shear force at end of tube, Ib \\
\hline q & The mean effective pressure on the header, $1 \mathrm{~b} / \mathrm{In}^{2}$ \\
\hline$r$ & Radius to any point, inches \\
\hline$r_{n}$ & Radial curvature at radius $r$, inches \\
\hline$r_{t}$ & Tangential curvature at radius $r$, inches \\
\hline $\mathrm{V}$ & Energy, in.-Ib \\
\hline$V_{p}$ & Strain energy in plate, in.-Ib \\
\hline $\mathrm{V}_{\mathrm{qw}}$ & Potential energy of load, in.-1b \\
\hline $\mathrm{w}^{2}$ & Deflection, inches \\
\hline$\theta$ & Angle, radians \\
\hline$\mu$ & Polsson's ratio, dimensionless \\
\hline$\Phi$ & Angle, radians \\
\hline
\end{tabular}

The expression for the strain energy in bending is $\mathrm{V}=1 / 2 \mathrm{M} \Phi(1)(2)(4)(5)$

Assume a circular plate loaded in a symmetrical manner and supported at its edge. Moments act on the sides of any element, as shown in the diagram below. It is necessary to relate the moments and angular deflection to the vertical deflection (w) in order to formulate a general solution of Equation 1.

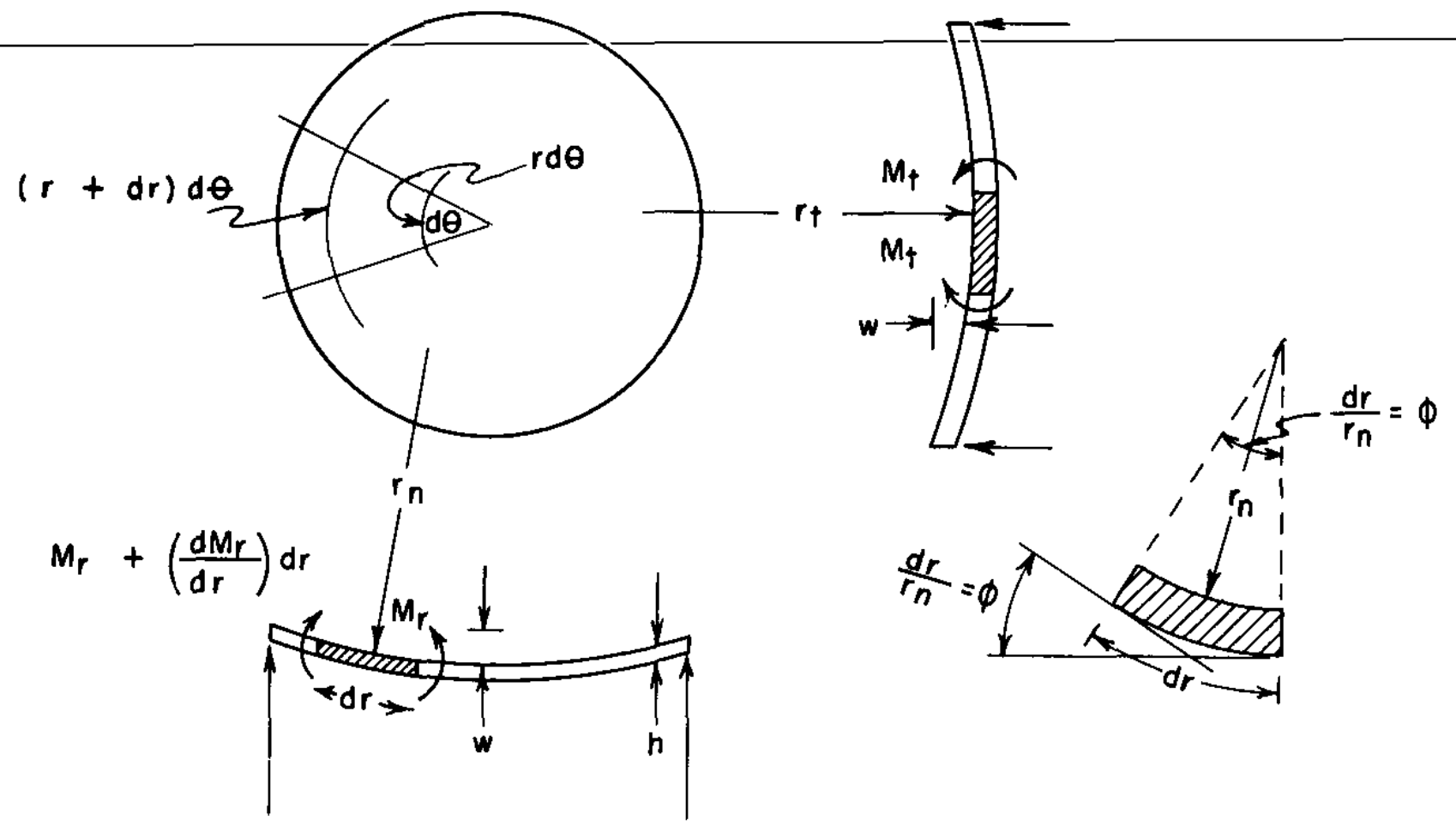


Couples act on the circumferential and radial sides of the plate element. Each of these couples is equal to the bending moment times the length over which the moment acts.

$$
\begin{aligned}
& \text { Radial curvature }=-\frac{\mathrm{d}^{2} \mathrm{w}}{\mathrm{dr}^{2}}=\frac{1}{\mathrm{r}_{\mathrm{n}}}(4)(5) \\
& \text { Corresponding angle }=-\frac{\mathrm{d}^{2} \mathrm{w}}{\mathrm{d} \mathrm{r}^{2}} \cdot \mathrm{dr} \text { for small angles } \\
& \text { Tangential curvature }=-\frac{1}{\mathrm{r}} \frac{\mathrm{d} w}{\mathrm{dr}}=\frac{1}{\mathrm{r}_{\mathrm{t}}} \\
& \text { Corresponding angle }=-\frac{1}{\mathrm{r}} \cdot \frac{\mathrm{dw}}{\mathrm{dr}} \cdot \mathrm{rd \theta}
\end{aligned}
$$

If $r$ is taken as the mean radius of the element, the radial couples can be expressed as follows:

$$
\begin{aligned}
& \text { Radial couple }=M_{r} \cdot r d \theta \\
& \text { Tangential couple }=M_{t} \cdot d r
\end{aligned}
$$

The work done by these two couples equals the strain energy. For the tangential moment,

$$
\mathrm{dV}_{\mathrm{t}}=-\frac{1}{2} \mathrm{M}_{\mathrm{t}} \mathrm{dr} \cdot \frac{1}{\mathrm{r}} \frac{\mathrm{dw}}{\mathrm{dr}} \cdot \mathrm{rd \theta} \text { (refer to Equation } 1 \text { ) }
$$

and for the radial moment,

$$
d V_{r}=-\frac{1}{2} M_{r} r d \theta \cdot \frac{d^{2} w}{d r^{2}} \cdot d r
$$

The total strain energy for the element of the plate is

$$
d V_{p}=-\frac{1}{2}\left(M_{t} \frac{d w}{d r}+M_{r} \cdot r \frac{d^{2} w}{d r^{2}}\right) d r d \theta
$$

The moments may be expressed in terms of the deflection and the plate constants as

$$
\begin{aligned}
& M_{r}=-D\left(\frac{d^{2} w}{d r^{2}}+\frac{\mu}{r} \frac{d w}{d r}\right) \\
& M_{t}=-D\left(\frac{1}{r} \frac{d w}{d r}+\mu \frac{d^{2} w}{d r^{2}}\right)
\end{aligned}
$$

The energy of the plate element is, therefore

$$
d V_{p}=\frac{D}{2}\left[\left(\frac{1}{r} \frac{d w}{d r}+\mu \frac{d^{2} w}{d r^{2}}\right) \frac{d w}{d r}+\left(\frac{d^{2} w}{d r^{2}}+\frac{\mu}{r} \frac{d w}{d r}\right) r \frac{d^{2} w}{d r^{2}}\right] d r d \theta
$$




\section{Verification of Derivation - Strain Energy in a Plate}

The strain energy in a circular plate (as shown by Equation 13 is a function of the deflection of the plate and the physical properties of the plate. The strain energy in the plate must be equal to the change in potential energy of the load from the undeflected to the deflected position of the plate. This fact presents a simple method for establjshing the validity of Equation 13. The method may be outline as follows:

(a) Assume a deflection curve for the plate subjected to a uniform pressure load. A convenient deflection equation is the one for a flat plate that is simply supported.

(b) Integrate the pressure-deflection curve over the entire plate surface. This integration yields the change in potential energy of the load.

(c) Substitute the required derivatives of the deflection curve and the physical constants into Equation 13. Integrate over the area of the plate and obtain the stra1 energy in bending for the plate.

It will now be shown that the results of (b) and (c) are equal from which it follows that Equation 13 for the strain energy in bending a circular flat plate is valid.

Assume that the plate is simply supported at the edge and is subjected to a uniform pressure load. The deflection equation for this case is

$$
w=\frac{g\left(a^{2}-r^{2}\right)}{64 D}\left(\frac{5+\mu}{1+\mu} a^{2}-r^{2}\right)
$$

where $a=$ outside radius of the plate

The potential energy change due to the pressure (unit force) and the plate-deflection-(distance-) Is

$$
\begin{aligned}
& \mathrm{dV}_{\mathrm{qw}}=\pi r \mathrm{dr} \cdot \mathrm{wq} \\
& \mathrm{V}_{\mathrm{qw}}=\pi \mathrm{q} \int_{0}^{r} r w d r
\end{aligned}
$$

Where the deflection equation is simple, such as Equation 14, the potential energy change as given by Equation 16 presents a convenien method for verifying the derived strain energy. The solution of Equation 13 must equal the solution of Equation 16 for the same conditions. Substitute Equation 14 in Equation 16 and integrate. The integration yields

$$
\begin{aligned}
v_{q w} & =\frac{\pi q^{2}}{64 D}\left[\frac{a^{6}(5+\mu)}{4(1+\mu)}-\frac{a^{6}}{12}\right] \\
\text { or } \quad v_{q w} & =\frac{0.0146 \pi q^{2} a^{6}}{D}
\end{aligned}
$$


For the assumed loading, Equation 18 must be equal to the integrated value of Equation 13 for the limits of $\theta$ from 0 to $2 \pi$ and $r$ from 0 to a. From Equation 14 for the deflection

$$
\begin{aligned}
\frac{d w}{d r}= & -\frac{r q}{32 D}\left(5.06 a^{2}-2 r^{2}\right) \\
\frac{d^{2} w}{d r^{2}}= & -\frac{q}{32 D}\left(5.06 a^{2}-6 r^{2}\right) \\
& \text { On substitution of these values in Equation } 13, \\
d v_{p}= & \frac{1}{2}\left[\frac{r q^{2}}{1024 D}\left(51.50 a^{4}-80.96 a^{2} r^{2}+40 r^{4}\right)\right. \\
& \left.+\frac{2 \mu r q}{1024 D}\left(25.75 a^{4}-40.48 a^{2} r^{2}+12 r^{4}\right)\right] \operatorname{drd} \theta
\end{aligned}
$$

The strain energy for the plate is determined by integration of Equation 21 between the limits of $\theta$ from 0 to $2 \pi$ and $r$ from 0 to $a$.

$$
v_{p}=\frac{0.0146 \pi q^{2} a^{6}}{D}
$$

The calculation confirms the validity of Equation 13 for the strain energy of the plate, since Equation 22 is identical with Equation 18. The deflection equation may take any form required for the particular loading and successive derivatives may be substituted in the energy expression, so long as the plate is circular.

\section{Strain Energy in Bending the Tubes}

The strain energy in each tube may be expressed in terms of the slope of the plate at the radial position of the particular tube. It is assumed that the top and bottom plates have identical deflection and curvature because the tubes are extremely rigid longitudinally.

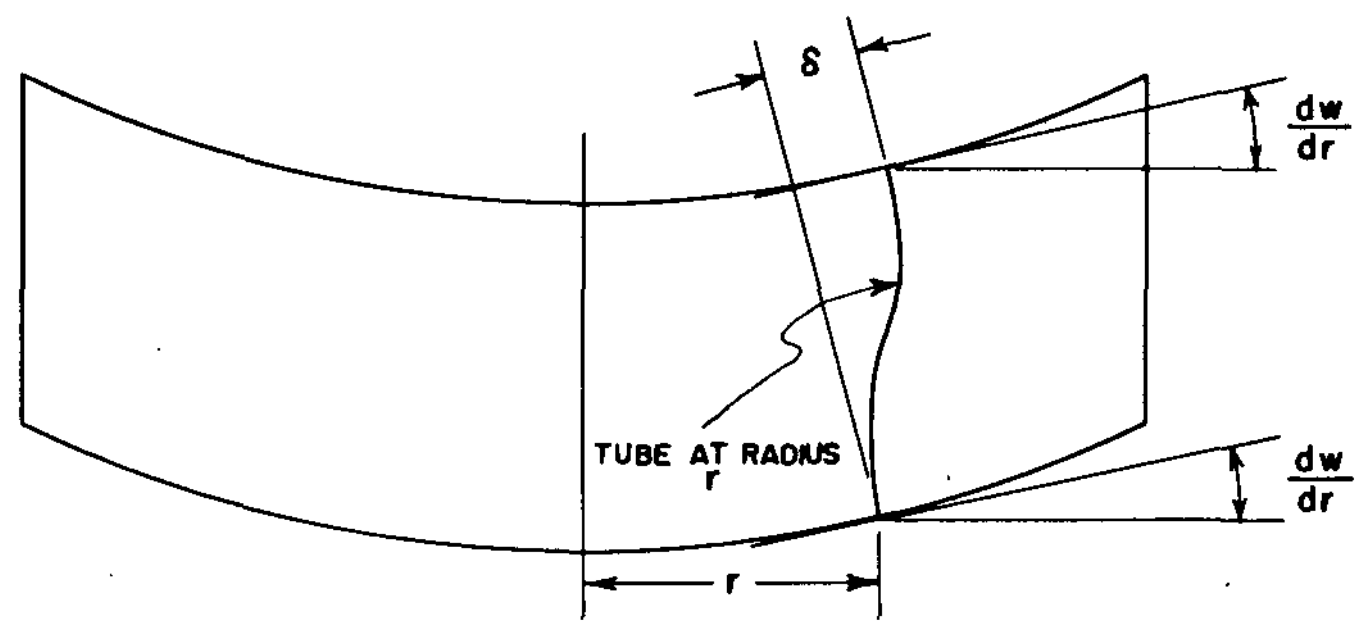

The above figure shows the relative deflections of the plates and tubes of the header. In order to illustrate the effect of distortion of the tube, a tube at radius $r$ is shown in the following figure: 


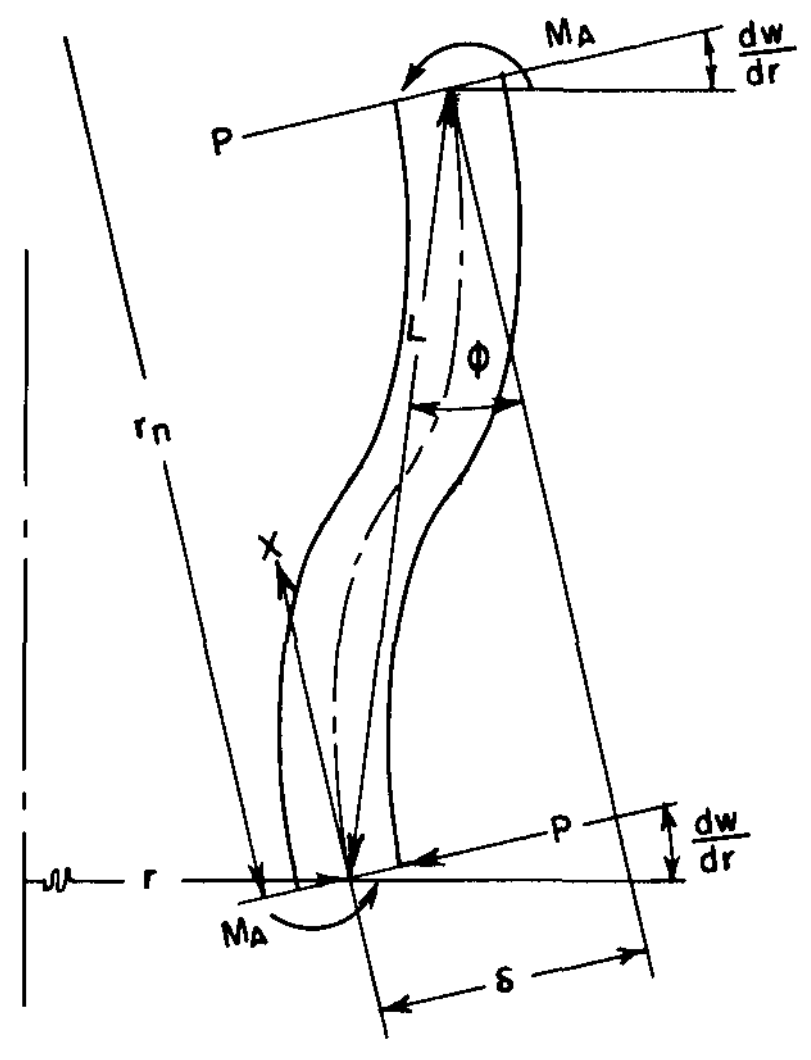

$$
\begin{aligned}
& \frac{\delta}{\mathrm{L}}=\sin \Phi \cong \tan \Phi \cong \frac{\mathrm{d} w}{\mathrm{dr}} \\
& \delta=\mathrm{L} \frac{\mathrm{d} w}{\mathrm{dr}}
\end{aligned}
$$

The linear deflection of the tube is given by the following equation:

$$
\delta=\frac{1}{\mathrm{EI}} \int_{0}^{\mathrm{L}}-\left(\mathrm{M}_{\mathrm{A}}-\mathrm{Px}\right) \mathrm{x} d \mathrm{x}
$$

which may be equated to Equation 24 as

$$
\delta=-\frac{1}{\mathrm{EI}}\left(\frac{\mathrm{M}_{\mathrm{A}}-\mathrm{E}^{2}}{2}-\frac{\mathrm{PL}^{3}}{3}\right)=\mathrm{L} \frac{\mathrm{dW}}{\mathrm{dr}}
$$

Since the sum of the moments in the tube is zero,

$$
\mathrm{PL}=2 \mathrm{M}_{\mathrm{A}}
$$

or

$$
\mathrm{P}=\frac{2 \mathrm{M}_{\mathrm{A}}}{\mathrm{L}}
$$

The strain energy in the tube is

$$
\begin{aligned}
& \mathrm{V}_{t}=\frac{1}{2} \int_{0}^{L} \frac{1}{\mathrm{EI}}\left(\mathrm{M}_{\mathrm{A}}-\mathrm{Px}\right)^{2} \mathrm{dx} \\
& \mathrm{V}_{t}=\frac{1}{2 \mathrm{EI}}\left(\mathrm{M}_{\mathrm{A}}^{2} \mathrm{~L}-\frac{2 \mathrm{M}_{\mathrm{A}} \mathrm{PL}}{2}+\frac{\mathrm{P}^{2} \mathrm{~L}^{3}}{3}\right)
\end{aligned}
$$


By substitution of Equation 28

$$
v_{t}=\frac{M_{A}^{2} L}{6 \mathrm{EI}}
$$

Since the bending moment for the tube is directly related to the slope of the plate, the tube energy may be related to the plate energy by combining Equations 26, 28, and 31.

$$
\begin{aligned}
& L \frac{d w}{d r}=-\frac{M_{A} L^{2}}{6 E I} \text { or } M_{A}=+\frac{6 E I}{L} \frac{d w}{d r} \\
& V_{t}=\frac{L}{6 E I}\left(\frac{6 E I}{L} \frac{d w}{d r}\right)^{2} \\
& V_{t}=\frac{6 E I}{L}\left(\frac{d w}{d r}\right)^{2}
\end{aligned}
$$

The total energy for all the tubes connecting the plates is

$$
\mathrm{V}_{t}=\sum_{0}^{r} \frac{6 \mathrm{EI}}{\mathrm{L}}\left(\frac{\mathrm{dw}}{\mathrm{dr}}\right)^{2} \mathrm{~N}
$$

Where $N$ is the number of tubes at any plate radius, $r$.

Total Strain Energy of the Header

The total strain energy of the header is the sum of the energies in the two plates and in the tubes, as given in Equations 13 and 35 .

$$
\begin{aligned}
V= & 2 V_{p}+V_{t} \\
V= & 2 \pi D \int_{0}^{r}\left[\left(\frac{1}{r} \frac{d w}{d r}+\mu \frac{d^{2} w}{d r^{2}}\right) \frac{d w}{d r}+\left(\frac{d^{2} w}{d r^{2}}+\frac{\mu}{r} \frac{d w}{d r}\right) r \frac{d^{2} w}{d r^{2}}\right] d r \\
& +\sum_{0}^{r} \frac{6 E I}{L}\left(\frac{d w}{d r}\right)^{2} N
\end{aligned}
$$

Equation 36, which is used to compute header deflections, is much simpler in application than in form. An outline of the method of solution may prove helpful. The steps are as follows:

(a) Assume a reasonable deflection curve for the plates. Neglect the tubes in making the assumption.

(b) Calculate the plate energy and the tube energy for the assumed deflection curve from Equation 36.

(c) Neglect the tubes and calculate the plate deflection from the assumed deflection curve. 
(d) Multiply the calculated plate deflection by the ratio of the plate energy to the total energy. The result is the header deflection due to load.

DERIVATION OF THE EQUATION FOR THE THERMAL DEFLECTION

The top tube sheet of the bottom shield of a Savannah River reactor is hotter than the bottom tube sheet during operation. Most headers operate under a similar condition; consequentiy, the problem may be considered general. The thermal deflection must be added to the pressure deflection in order to obtain the total deflection. The following derivation for thermal deflection is general.

Nomenclature

a Coefficient of thermal expansion, in./in. $-{ }^{\circ} \mathrm{C}$

$d_{0}$ Outside diameter of plate when cold, inches

$d_{1}$ Outside diameter of plate when hot, inches

$\mathrm{H}$ Header height, inches

$\Delta \mathrm{T}$ Mean temperature difference, top plate minus bottom plate, ${ }^{\circ} \mathrm{C}$

$R$ Radius of curvature, inches

$\Phi$ Angle, radians

$\delta_{\Delta \mathrm{T}}$ Thermal deflection at center of header, Inches

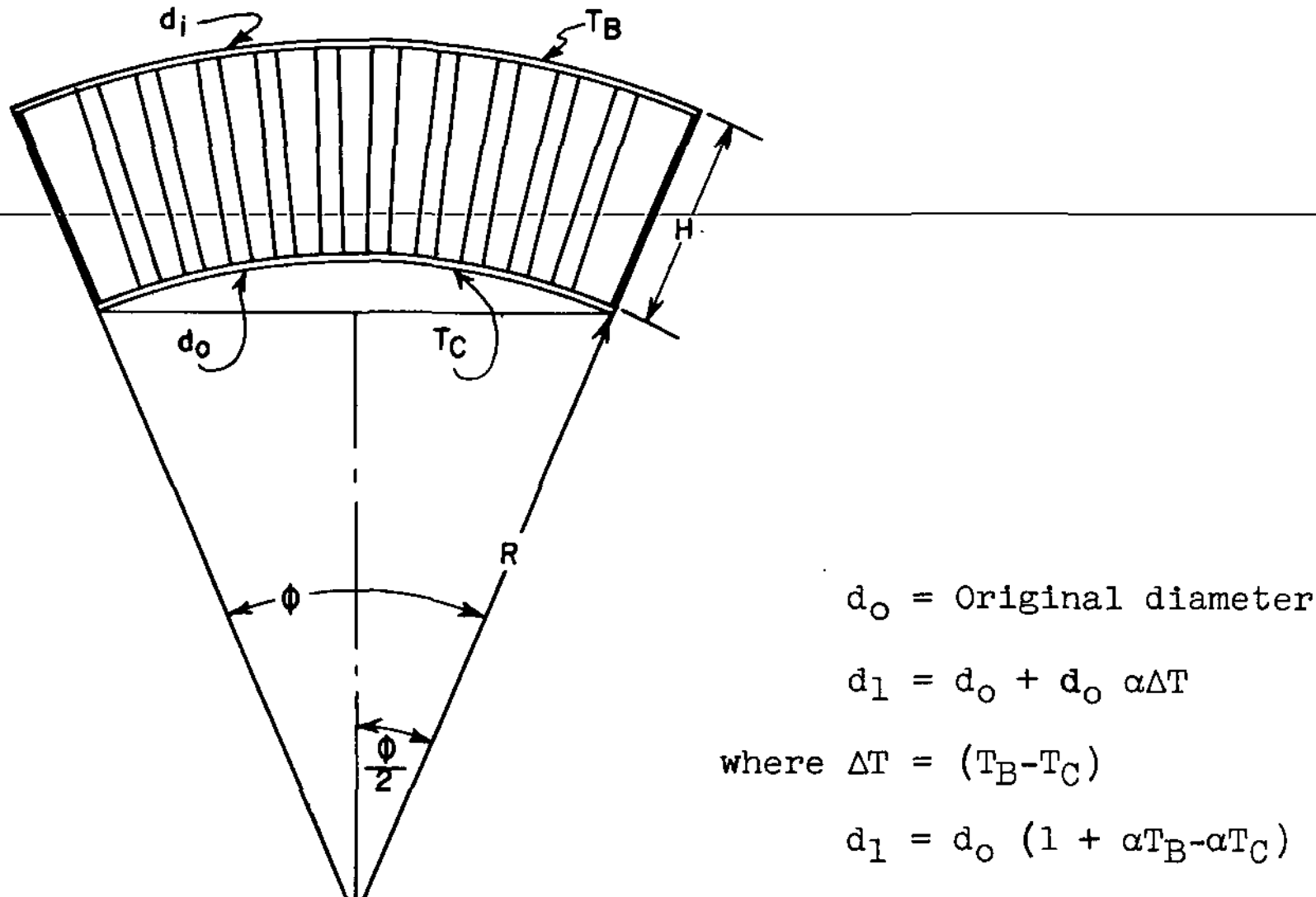


$\mathrm{d}_{\mathrm{O}}=\mathrm{R} \Phi$

$\mathrm{d}_{1}=(\mathrm{R}+\mathrm{H}) \Phi=\mathrm{d}_{0}(1+\alpha \Delta \mathrm{T})$

$\delta_{\Delta T}=R\left(1-\cos \frac{\Phi}{2}\right) \cong \frac{R \Phi^{2}}{8}$

By eliminating $R$ and $\Phi$ from Equation 42 through the use of Equations 40 and 41 , the deflection becomes

$$
\delta_{\Delta \mathrm{T}}=\frac{\mathrm{H}}{\alpha \Delta \mathrm{T}}\left[1-\cos \left(\frac{\mathrm{d}_{\mathrm{O}} \alpha \Delta \mathrm{T}}{2 \mathrm{H}}\right)\right] \cong \frac{\alpha \Delta \mathrm{T} \cdot \mathrm{d}_{\mathrm{O}}{ }^{2}}{8 \mathrm{H}}
$$

Equation 43 is general for thermal deflection of headers.

TOTAL DEFLECTION

The final relationship for the total deflection, $\Delta$, of a two-plate header joined by tubes and subjected to pressure and thermal loading is obtained by adding the pressure deflection to the thermal deflection.

$\Delta=\mathrm{W}_{\mathrm{q}}+\delta_{\Delta \mathrm{T}}$

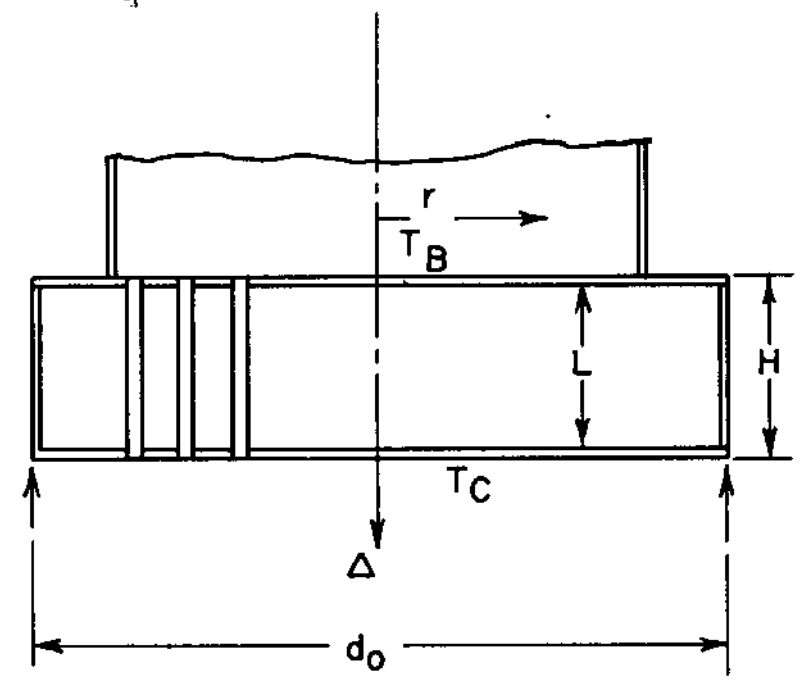

$$
\begin{aligned}
\Delta \mathrm{T} & =\left(\mathrm{T}_{\mathrm{B}}-\mathrm{T}_{\mathrm{C}}\right) \\
\mathrm{N} & =\text { Number of tubes } \\
\mathrm{E} & =\text { Young's modulus } \\
\mathrm{I} & =\text { Tube area moment } \\
\alpha & =\text { Co inertia } \\
\mathrm{D} & \text { thermal expansion } \\
\mathrm{D} & =\text { Flexural rigidity } \\
& =\frac{\mathrm{EI}}{\left(1-\mu^{2}\right)}
\end{aligned}
$$

SAMPLE CALCULATION OF HEADER DEFLECTION

The pressure deflection of the bottom shield of the Savannah River reactors may be calculated by application of Equation 44. The essential data are:

Material - Stainless steel

Tube sheets - 1 inch thick

No. of tubes - 673

$\mathrm{H}=39$ inches

$\alpha=14.4 \times 10^{-6}$ in./in. $-{ }^{\circ} \mathrm{C}$

$E=30 \times 10^{6} \mathrm{lb} / \mathrm{In}$ ? (for tubes) 
$I=37$ inches (for tubes)

$I=6.30 \mathrm{in}$. (for tubes)

Shield outside diameter, $d_{0}=224$ inches

Tank radius $=96$ inches

The tubes are arranged on a triangular lattice. To simplify the calculations, it was assumed that the tubes are arranged in concentric circles at radial increments of five inches, and that each circle contains four tubes more than the preceding circle. Thus there are four tubes in the first circle, eight in the second, and so on. Although this procedure totals 684 tubes instead of the actual 673, the difference is insignificant. It was assumed that the deflection equation for the plates is reasonably represented by Equation 14 and that the bottom shield is simply supported at the reactor tank. The bottom shield is extensively reinforced from the edge of the plates to the reactor tank, and should experience negligible deflection beyond the tank radius.

Calculation of Plate Energy

The plate energy for the top and bottom tube sheet of the bottom shield is

$$
V_{P}=\frac{0.0146 \pi q^{2} a^{6}}{D} \text { (per plate) }
$$

(See Equation 22)

In terms of the pressure, this energy is

$$
\begin{aligned}
& \mathrm{V}_{\mathrm{P}}=\frac{0.0146 \times 96^{6} \times \pi \mathrm{q}^{2}}{\mathrm{D}} \text { (per plate) } \\
& \mathrm{D}=2.56 \times 10^{6} \\
& \mathrm{~V}_{\overline{\mathrm{p}}}=\frac{7.22 \times 10^{10} \mathrm{q}^{2}}{2.56 \times 10^{6}}=-2.82 \times 10^{4} \mathrm{q}^{2} \text { (for the two plates) }
\end{aligned}
$$

Calculation of Tube Energy

The calculation of the tube strain energy, which is the solution to Equation 13, is summarized in Table I on Page 31 . From this table,

$$
V_{t}=10874 \times 10^{16} \frac{q^{2}}{D^{2}}=1660 \times 10^{4} q^{2}
$$

The results of the tube and plate energy calculations show that the bottom shield under hydraulic pressure deflects only $1 / 600$ times as much as the plates alone would deflect at the same pressure. To calculate the deflection of the bottom shield under pressure, the calculated free deflection of the two plates is divided by 600 .

The free plate deflection is assumed to be represented by the deflection equation of a circular plate that is simply supported at the edge. 
$w_{\max }=\frac{\mathrm{qa}^{4}}{128 \mathrm{D}}\left(\frac{5+\mu}{1+\mu}\right)$

for two plates at $r=0$

(See Equation 14, p.10)

The deflection per unit pressure is

$$
w_{\max }=\frac{96^{4} \times 5.3}{128 \times 2.560 \times 10^{6} \times 1.3}=1.05 \mathrm{in} . / \mathrm{psi}
$$

The bottom shield pressure deflection is

$$
w_{q}=\frac{1.05 x V_{p}}{V_{p}+V_{t}}=\frac{1.05}{600}=0.0017 \mathrm{in} . / p s i
$$

When $\mathrm{w}_{\mathrm{g}}$ is positive, the deflection is downward.

The calculation may also be performed by replacing the flexural rigidity, $D$, in the deflection equation of the plates with an effective flexural rigidity for the header, $D_{0}$. The effective flexural rigidity is

$$
D_{0}=2.56 \times 600 \times 10^{6} \mathrm{lb}-\mathrm{in}{ }^{2}
$$

\section{Calculation of Thermal Deflection}

$$
\begin{aligned}
& \text { From Equation } 43, \text { the thermal deflection is } \\
\delta_{\Delta \mathrm{T}} \cong & \frac{a \Delta \mathrm{T} \cdot \mathrm{d}_{\mathrm{O}}}{8 \mathrm{H}} \\
\delta_{\Delta \mathrm{T}} \cong & \frac{-14.4 \times 10^{-6} \times 224^{2}}{8 \times 39} \Delta \mathrm{T} \cong-0.0022 \Delta \mathrm{T} \text { inches }
\end{aligned}
$$

The negative sign signifies upward deflection for a positive $\Delta T$.

Total Deflection

The total deflection of the bottom shield is equal to the sum of the pressure deflection and the thermal deflection.

$$
\begin{aligned}
& \Delta=\mathrm{w}_{\mathrm{q}}+\delta_{\Delta \mathrm{T}} \\
& \Delta=0.0017 \mathrm{q}-0.0022 \Delta \mathrm{T}
\end{aligned}
$$

The relationship between the deflection and the pressure and temperature is shown in Figure 2 . 
The reactor tank, which is a cylindrical stainless steel vessel, is welded circumferentially to the top tube sheet of the bottom shield to form a "T" joint. The geometry of the reactor tank is shown In Figure 1. Bending stresses at the " $\mathrm{T}$ " joint are caused by the static head of water in the tank, the thermal distortion of the tank waIl, and the thermal and pressure deflection of the bottom shield. The following figure illustrates the " $\mathrm{T}$ " joint and shows the free-body diagram for the forces and moments.

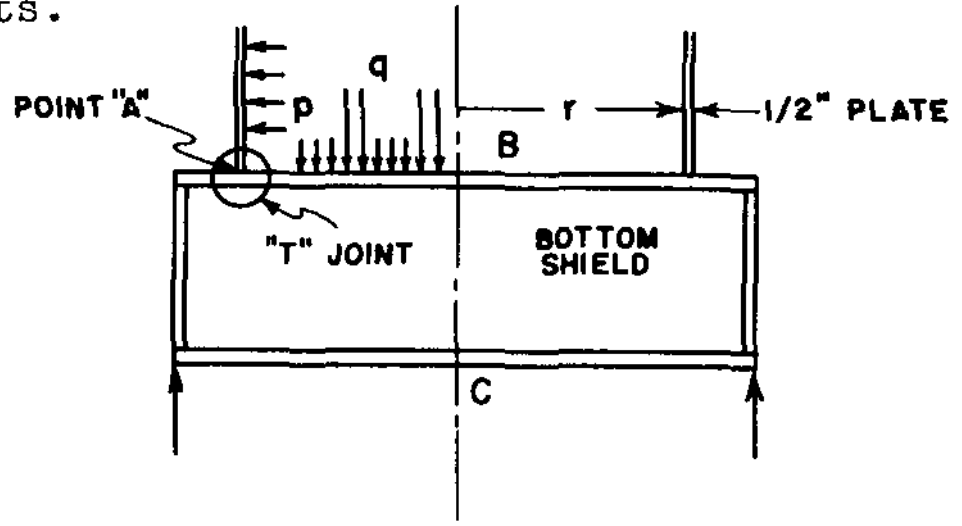

\section{DEFLECTIONS AND ROTATIONS AT POINT "A"}

PRESSURE DEFLECTION (p)

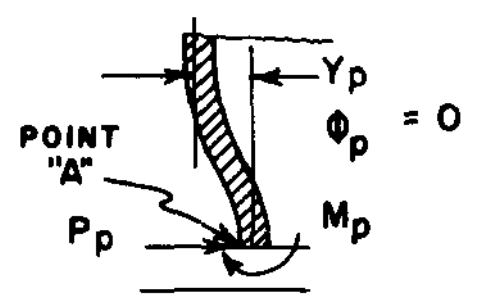

THERMAL DEFLECTION $\left(T_{B}>T_{A}\right)$

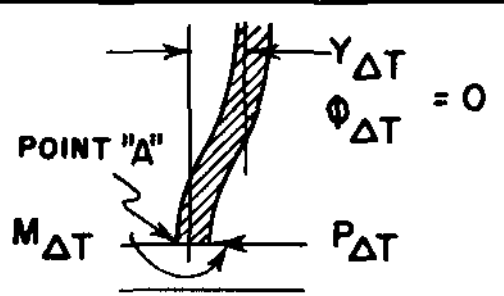

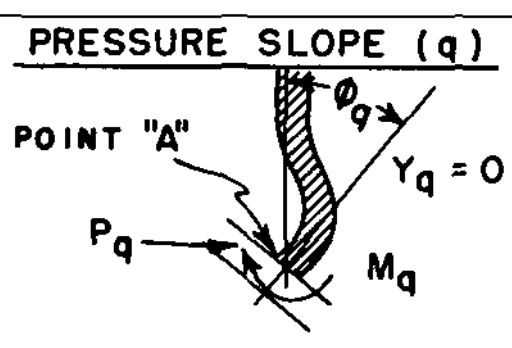

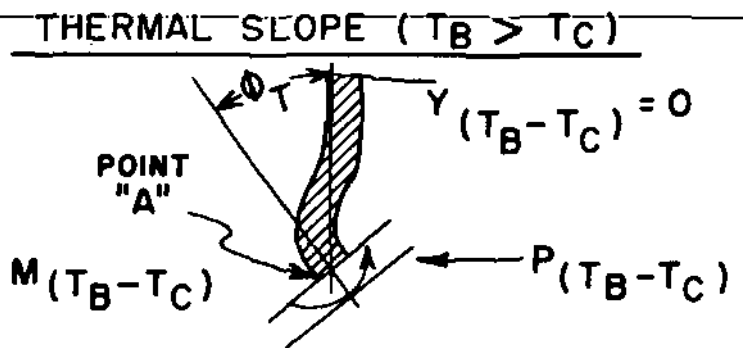

DEFORMATION OF THE "T" JOINT

Moments and Forces at the "T" Joint

The bending stress at point "A" may be determined by superposition. The method is simply stated by the following relationships, in which $\mathrm{M}_{\mathrm{A}}$ is the total moment at point " $\mathrm{A}$ ".

$$
M_{A}=M_{p}+M_{\Delta T}+M_{q}+M_{\left(T_{B}-T_{C}\right)}\left(\sigma_{A}=\frac{M_{A} c}{I}=\frac{M_{A} \frac{h}{2}}{\frac{b h^{3}}{12}}=\frac{6 M_{A}}{h^{2}}\right.
$$


$1 \mathrm{~b} / \mathrm{in}^{2}$

The moments, $M$, are in $1 \mathrm{~b}-\mathrm{in.} / \mathrm{In}$. , and the stress $\sigma_{\mathrm{A}}$ is in

$\mathrm{P}_{\mathrm{A}}=\mathrm{P}_{\mathrm{p}}+\mathrm{P}_{\Delta \mathrm{T}}+\mathrm{P}_{\mathrm{q}}+\mathrm{P}\left(\mathrm{T}_{\mathrm{B}}-\mathrm{T}_{\mathrm{C}}\right)=$ Total shear force at point "A". The shear force units, $P$, are $1 b / i n$. of circumference.

The moments and forces may be calculated in terms of the temperatures and pressures, because the tank is a long cylinder subject to standard deflection and slope equations.

The nomenclature in the derivation and solution of the equations for the bending stress is:

$\mathrm{P}_{\mathrm{A}}=$ Shear force at the joint per inch of circumference, Ib/in.

$\mathrm{M}_{\mathrm{A}}=$ Bending moment, $1 \mathrm{~b}-\mathrm{in} \cdot / \mathrm{in}_{3}$

$D=$ Flexural rigidity $=\frac{E h^{3}}{12\left(1-\mu{ }^{2}\right)}$

$E=$ Young's modulus, $1 \mathrm{~b} / \mathrm{in}$ ?

$\mathrm{H}=$ Bottom shield height, inches

$\mu=$ Poisson's ratio, dimensionless

$B=\sqrt{\frac{3\left(1-\mu^{2}\right)}{r^{2} h^{2}}} ; r=$ tank radius, inches

$\mathrm{y}=$ Radial deflection, inches. Positive toward center of tank

$\mathrm{x}=$ Longitudinal dimension

$\mathrm{y}_{\mathrm{p}}=$ Pressure deflection, Inches

$\mathrm{y}_{\Delta \mathrm{T}}=$ Thermal deflection, inches

$\alpha=$ Coefficient of expansion, in./1n. $-{ }^{\circ} \mathrm{C}$

$\mathrm{T}=$ Temperature, ${ }^{\circ} \mathrm{C}$

$\mathrm{p}$ = Static head, psig

$\frac{d y}{d x}=$ Slope of tank wall $=\frac{d w}{d r}$ of the bottom shield at the joint

Derivation of Moments and Forces at the "T" Joint

Timoshenko (4) shows that the deflection of a long cylinder is represented by the following equation:

$$
y=\frac{e^{-\beta x}}{2 \beta^{3} D}\left[P_{A} \cos \beta x-\beta M_{A}(\cos \beta x-\sin \beta x)\right]
$$

The deflection and slope at the "T" foint are determined by substituting $x=0$ into Equation 45 and into the derivative of Equation 45 .

$$
\begin{aligned}
y & =\frac{P_{A}-\beta M_{A}}{2 \beta{ }^{3} D} \text { at } x=0 \\
\frac{d y}{d x} & =-\frac{P_{A}-2 \beta M_{A}}{2 \beta^{2} D} \text { at } x=0
\end{aligned}
$$


The deflection of the tank wall at $x=0$ is a known function of the pressure on the tank wall and the temperature difference between the wall and the top tube sheet. Equation 46 then contains two unknowns, the shear force and the bending moment. The slope of the tank wall at $\mathrm{x}=0$ was assumed equal to the slope of the bottom shield at $r=a$. Because the slope of the tank wall is a known function of the pressure on the bottom shield and the temperature difference between the top tube sheet and the bottom tube sheet, Equation 47 contains the same two unknowns as Equation 46. The shear force and bending moment may be determined from these two equations containing two unknowns.

\section{Deflection at the "T" Jolnt}

For an unrestrained cylinder in the form of an open tank, the membrane stresses caused by pressure are:

$$
\begin{aligned}
& \sigma_{\mathrm{x}}=0 \text { (5) where } \sigma_{\mathrm{x}}=\text { stress along the cylinder } \\
& \sigma_{\mathrm{y}}=\frac{\mathrm{pr}}{\mathrm{h}}(5) \text { where } \sigma_{\mathrm{y}}=\text { Stress around the cylinder }
\end{aligned}
$$

The radial displacement of the cylinder is determined from the circumferential strain, $\epsilon_{\mathrm{y}}$.

$$
\epsilon_{\mathrm{y}}=\frac{1}{\mathrm{E}}\left(\sigma_{\mathrm{y}}-\mu \sigma_{\mathrm{x}}\right)
$$

The circumferential strain is equal to the radial strain,

$$
\begin{aligned}
\epsilon_{y} & =\frac{\Delta r}{r} \\
\Delta r & =r \epsilon_{y}=\frac{r}{E}\left(\sigma_{y}-\mu \sigma_{x}\right)
\end{aligned}
$$

By substitution of Equations 48 and 49 in Equation 52

$$
\Delta r=\frac{\mathrm{pr}^{2}}{\mathrm{hE}}
$$

The radial displacement caused by the pressure is completely restrained at $x=0$ by the top tube sheet of the bottom shield. Because of this restraint, a positive pressure deflection exists at $\mathrm{x} \cdot=0$.

$$
\mathrm{y}_{\mathrm{p}}=\Delta \mathrm{r}=+\frac{p \mathrm{r}^{2}}{\mathrm{hE}}
$$

The thermal distortion also results in radial wall displacement at $x=0$. The thermal displacement must be added to the pressure deflection.

$$
\mathrm{y}_{\Delta \mathrm{T}}=-\mathrm{r} \alpha\left(\mathrm{T}_{\mathrm{B}}-\mathrm{T}_{\mathrm{A}}\right)
$$

The sign is negative for all values of $\mathrm{T}_{B}>\mathrm{T}_{\mathrm{A}}$, indicating that the wall of the tank is displaced outward at $x=0$, if the top tube sheet is hotter than the tank wall. 


$$
\begin{aligned}
& \mathrm{y}=\mathrm{y}_{\mathrm{p}}+\mathrm{y}_{\Delta \mathrm{T}} \\
& \mathrm{y}=\frac{\mathrm{pr}^{2}}{\mathrm{hE}}-\mathrm{r \alpha}\left(\mathrm{T}_{\mathrm{B}}-\mathrm{T}_{\mathrm{A}}\right) \text { at } \mathrm{x}=0
\end{aligned}
$$

By Equation 45 at $x=0$,

$$
y=\frac{1}{2 B^{3} D}\left(P_{A}-B M_{A}\right)
$$

therefore, the deflection equation is

$$
\frac{\mathrm{pr}^{2}}{\mathrm{hE}}-\mathrm{ra}\left(\mathrm{T}_{\mathrm{B}}-\mathrm{T}_{\mathrm{A}}\right)=\frac{1}{2 \beta^{3} \mathrm{D}}\left(\mathrm{P}_{\mathrm{A}}-\beta \mathrm{M}_{\mathrm{A}}\right)
$$

\section{Slope at the "T" Jolnt}

The radial pressure deflection and the thermal deflection result in zero change in the slope of the tank wall at $\mathrm{x}=0$. The slope of the shield at the "T" joint is, therefore, equal to the slope of the tank wall at $x=0$. The slope of the tank wall at $x=0$ is

$$
\begin{aligned}
& -\frac{d y}{d x}=\frac{d w}{d r}+\frac{\Phi}{2}=-\frac{3.06 r 3 g}{32 D}+\frac{d_{0} \alpha \Delta T}{2 H} \\
& \text { (see Equations } 41 \text { and 19) }
\end{aligned}
$$

The algebraic sign of the slope is fixed by noting that pressure deflection of the bottom shield rotates the lower end of the tank wall through a positive angle. The reverse is true for the thermal deflection when the top of the shield is hotter than the bottom. The following equations were presented in the analysis of deflection of the bottom shield.

$$
\begin{aligned}
& +\frac{\Phi}{2}=\frac{\mathrm{d}_{\mathrm{O}} \alpha\left(\mathrm{T}_{\mathrm{B}}-\mathrm{T}_{\mathrm{C}}\right)}{2 \mathrm{H}}=\frac{192 \times 14.4 \times 10^{-6}\left(\mathrm{~T}_{\mathrm{B}}-\mathrm{T}_{\mathrm{C}}\right)}{2 \times 39} \\
& +\frac{\Phi}{2}=0.355 \times 10^{-4}\left(\mathrm{~T}_{\mathrm{B}}-\mathrm{T}_{\mathrm{C}}\right) \\
& \frac{\mathrm{dw}}{\mathrm{dr}}=-\frac{3.06 \mathrm{r}^{3} \mathrm{q}}{32 \mathrm{D}_{\mathrm{O}}}=-\frac{3.06 \times 96^{3} \mathrm{q}}{2 \times 32 \times 600 \times 2.560 \times 10^{6}}=-0.273 \times 10^{-4} \mathrm{q}
\end{aligned}
$$

where $D_{0}=$ Effective flexural rigidity. (See p. 17.)

The slope at $\mathrm{x}=0$ is

$$
\frac{d y}{d x}=-0.355 \times 10^{-4}\left(T_{B}-T_{C}\right)+0.273 \times 10^{-4} q
$$

By combining Equations 47 and 63

$$
-0.355 \times 10^{-4}\left(\mathrm{~T}_{\mathrm{B}}-\mathrm{T}_{\mathrm{C}}\right)+0.273 \times 10^{-4} \mathrm{q}=-\frac{1}{2 \beta^{2} \mathrm{D}}\left[\mathrm{P}_{\mathrm{A}}-2 \beta \mathrm{M}_{\mathrm{A}}\right]
$$


Moment at the "r" Joint

$\mathrm{P}_{\mathrm{A}}$ may be solved in terms of $\mathrm{M}_{\mathrm{A}}$ by Equation 59.

$-\mathrm{P}_{\mathrm{A}}=2 \beta^{3} \mathrm{D}\left[-\frac{p r^{2}}{\mathrm{hE}}+\mathrm{ra}\left(\mathrm{T}_{\mathrm{B}}-\mathrm{T}_{\mathrm{A}}\right)\right]+\beta \mathrm{M}_{\mathrm{A}}$

From substitution of 65 in 64 the bending moment, $\mathrm{M}_{A}$, is

$-M_{A}=2 \beta D\left[-\frac{\beta r^{2} p}{h E}+r \beta \alpha\left(T_{B}-T_{A}\right)+35.5 \times 10^{-6}\left(T_{B}-T_{C}\right)-27.3 \times 10^{-6} q\right]$

All coefficients in the temperature and pressure terms are functions of the geometry of the tank wall and the properties of the material.

Constants in Bending. Moment Equation 66

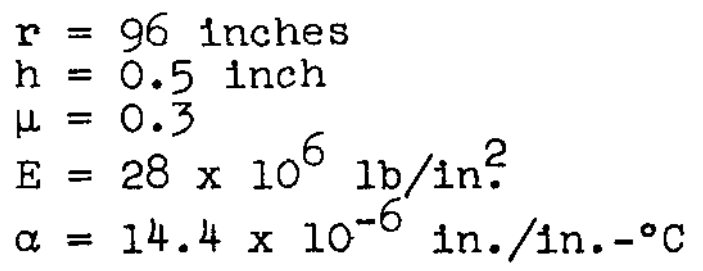

All. temperatures are in ${ }^{\circ} \mathrm{C}$; pressure units are psig

$$
\begin{aligned}
& B=\sqrt[4]{\frac{3\left(1-\mu^{2}\right)}{r^{2} h^{2}}}=\sqrt[4]{\frac{3 \times 0.91}{96^{2} \times 0.5^{2}}}=0.1854 \\
& D=\frac{E^{3}}{12\left(1-\mu^{2}\right)}=\frac{28 \times 10^{6} \times 0.5^{3}}{12 \times 0.91}=0.321 \times 10^{6}
\end{aligned}
$$$$
\frac{2 \beta^{2} \overline{\mathrm{Dr}}^{2}}{\mathrm{hE}}=\frac{2 \times 0.1854^{-2} \times 0.321 \times 96^{2} \times 10^{6}}{0.5 \times 28 \times 10^{6}}=14.5
$$$$
2 \beta^{2} \text { Dr } \alpha=2 \times 0.1854^{2} \times 0.321 \times 96 \times 14.4=30.6
$$$$
2 \beta D \times 27.3 \times 10^{-6}=3.3
$$$$
2 \beta D \times 0.355 \times 10^{-4}=4.22
$$

Equation 66 with the constants substituted is

$$
\mathrm{M}_{\mathrm{A}}=14.5+30.6\left(\mathrm{~T}_{\mathrm{B}}-\mathrm{T}_{\mathrm{A}}\right)+4.22\left(\mathrm{~T}_{\mathrm{B}}-\mathrm{T}_{\mathrm{C}}\right)-3.3 \mathrm{q}
$$

The bending stress at the "T" Joint is computed by the following equation:

$$
\sigma_{A}=-\frac{6 M_{A}}{h^{2}}=24 \quad\left[-14.5 p+30.6\left(T_{B}-T_{A}\right)+4.22\left(T_{B}-T_{C}\right)-3.3 q\right]
$$


The importance of the deflection equations for the bottom shield is emphasized by Equation 68. The third and fourth terms occur in the stress equation because the bottom shield bows as it deflects vertically and bends the tank wall. The relationship between the stress at the " $T$ " joint and the pressures and temperatures is shown in Figure 3.

\section{Sample Calculation of Stress at the "T" Jolnt}

The following example illustrates the application of Equation 68 to the calculation of the stress at the "T" folnt. Assume the following data:

$$
\begin{aligned}
& \mathrm{p} \quad=\text { Static head }=7 \mathrm{psig} \\
& \mathrm{T}_{\mathrm{A}}=57^{\circ} \mathrm{C} \\
& \mathrm{T}_{\mathrm{B}}=82^{\circ} \mathrm{C} \\
& \mathrm{T}_{\mathrm{C}}=41^{\circ} \mathrm{C} \\
& \mathrm{Z} \text { = Dynamic pressure above each tube in the bottom shield } \\
& =22 \mathrm{ps} 1 \mathrm{~g} \\
& \mathrm{q}=\text { Mean effective pressure on the bottom shield } \\
& q \\
& =\frac{\mathrm{Z} x \text { tube area }+\mathrm{p} \text { (area of the shield - the area of the tubes) }}{\text { area of the shield }}
\end{aligned}
$$

By Equation 68

$$
\begin{aligned}
& \sigma_{A}=24[-14.5 \times 7+30.6(82-57)+4.22(82-41)-3.3 \times 9.5] \\
& \sigma_{A}=+19,3001 \mathrm{~b} / 1 \mathrm{n} ?
\end{aligned}
$$

The stress at point " $A$ " Is tension in bending for the assumed operating data.

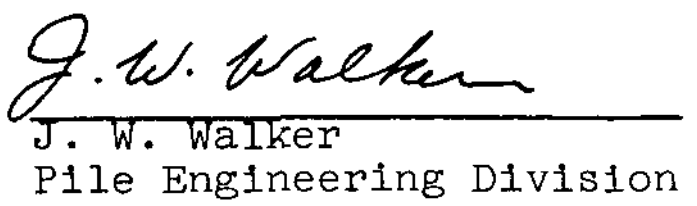




\section{BIBLIOGRAPHY}

1. Den Hartog, J. P. Advanced Strength of Materials. First Edition, New York: McGraw-H111 Book Co., Inc. (1952).

2. Southwe1l, R. V. Theory of Elasticity. Second Edition, London: Oxford University Press (1941).

3. Timoshenko, S. Strength of Materials Part I. Second Edition, New York: D. Van Nostrand Co., Inc. (1941).

4. Timoshenko, S. Strength of Materials Part II. Second Edition, New York: D. Van Nostrand Co., Inc. (1943).

5. TImoshenko, S. Theory of Plates and Shells. Englneering Socleties Monographs. First Edition, New York: McGraw-Hill Book Co., Inc. (1940). 


\section{NOMENCLATURE}

Symbol Definition

Units

A

a

b

B

c

C

D

$d_{1}$

$a_{0}$

E

h

$\mathrm{H}$

I

M

$\mathrm{M}_{\mathrm{A}}$

$M_{r}$

$M_{t}$

N

$\mathrm{P}$

$q$

R

$r$

$r_{n}$

$r_{t}$
Position of weldment between the tank wall and the tube sheet (called the "T" joint)

outside radius of plate

inches

Width of strip of cylinder $=1$ inch

Inches

Top tube sheet location

inches

Distance from neutral axis to extreme fibre for plate

inches

Bottom tube sheet location

Flexural rigidity

In. $-1 b$

Outside diameter of the plate when hot

inches

Outside diameter of the plate when cold

inches

Young's modulus

Ib/in?

plate thickness

Inches

Header thickness

inches

Tube length

Inches

Bending moment

Ib-in.

Bending moment on end of tubes

Ib-in.

Radial bending moment on plate

Ib-in./In.

Tangentlal bending moment on plate

Ib-in./in.

Number of tubes in header

Shear force on tube

Ib

Mean effective pressure on top tube sheet

Ib/in?

Radius of curvature of shield

inches

Radius to any point

Inches

Radial radius of curvature

inches

Tangential radius of curvature 


\section{NOMENCLATURE (Continued)}

\begin{tabular}{|c|c|c|}
\hline Symbol & Definition & Units \\
\hline $\mathrm{T}, \mathrm{T}_{\mathrm{A}}, \ldots$ & Temperature & ${ }^{\circ} \mathrm{C}$ \\
\hline $\mathrm{V}$ & Strain energy & in. - Ib \\
\hline$V_{\mathrm{p}}$ & Plate strain energy & in. $-1 b$ \\
\hline$v_{\text {qW }}$ & Potential energy of load & in. $-1 b$ \\
\hline$V_{t}$ & Tube strain energy & in. $-1 b$ \\
\hline $\mathrm{w}$ & Deflection & inches \\
\hline$w_{\max }$ & Vertical deflection of a free plate & inches \\
\hline $\mathrm{w}_{\mathrm{q}}$ & Pressure deflection of the header & inches \\
\hline$\delta$ & Relative deflection of tube ends & inches \\
\hline$\delta_{\Delta \mathrm{T}}$ & Vertical thermal deflection at center of shield & inches \\
\hline$\Delta$ & Total deflection of header & inches \\
\hline$\Delta T$ & $\begin{array}{l}\text { Mean temperature difference, top plate minus } \\
\text { bottom plate }\end{array}$ & ${ }^{\circ} \mathrm{C}$ \\
\hline$\alpha$ & Coefficient of thermal expansion & in. $/$ in. $-{ }^{\circ} \mathrm{C}$ \\
\hline$\theta$ & Angle & -radians \\
\hline$\mu$ & Poisson's ratio & \\
\hline$\Phi$ & Angle & radians \\
\hline \multicolumn{3}{|c|}{ Reactor Tank Wall } \\
\hline $\mathrm{M}_{\mathrm{A}}$ & Bending moment at the "T" joint & ib-in./in. \\
\hline $\mathrm{M}_{\mathrm{p}}$ & Bending moment at "A" caused by the static head & $i b-i n . / i n$. \\
\hline$M_{\mathrm{T}}$ & $\begin{array}{l}\text { Bending moment at "A" caused by thermal deflection } \\
\text { of the header }\end{array}$ & $1 b-1 n \cdot / 1 n$ \\
\hline $\mathrm{M}_{\mathrm{q}}$ & $\begin{array}{l}\text { Bending moment at "A" caused by pressure } \\
\text { deflection of the header }\end{array}$ & ib-in./in. \\
\hline $\mathrm{M}_{\mathrm{T}_{\mathrm{B}}}-\mathrm{T}_{\mathrm{C}}$ & $\begin{array}{l}\text { Bending moment at "A" caused by the thermal } \\
\text { deflection of the tank wall }\end{array}$ & ib-in./1n. \\
\hline $\mathrm{h}$ & Thickness of the tank wall & Inches \\
\hline
\end{tabular}




\section{NOMENCLATURE (Continued)}

Symbol Definition

Units

$P \quad$ Shear force at "A" (subscripts have the same meaning as the moment subscripts)

$1 b /$ in.

$\mathrm{p}$

Static pressure

1b/in?

Radius of the tank

inches

y

Radial deflection at the tank wall (same subscript meaning)

inches

c

Distance from neutral axis to extreme fibre $=h / 2$ inches

I

Moment of inertia of a one-inch wide strip of wall plate

in.

$\sqrt[4]{\frac{3\left(1-\mu^{2}\right)}{r^{2} h^{2}}}$

in:-1

Strain

in./in.

Coefficient of expansion

in. $/$ in. $-{ }^{\circ} \mathrm{C}$

Stress (subscripts have the same meaning as the moment subscripts)

$1 b /$ in? 


\section{FIGURE I}

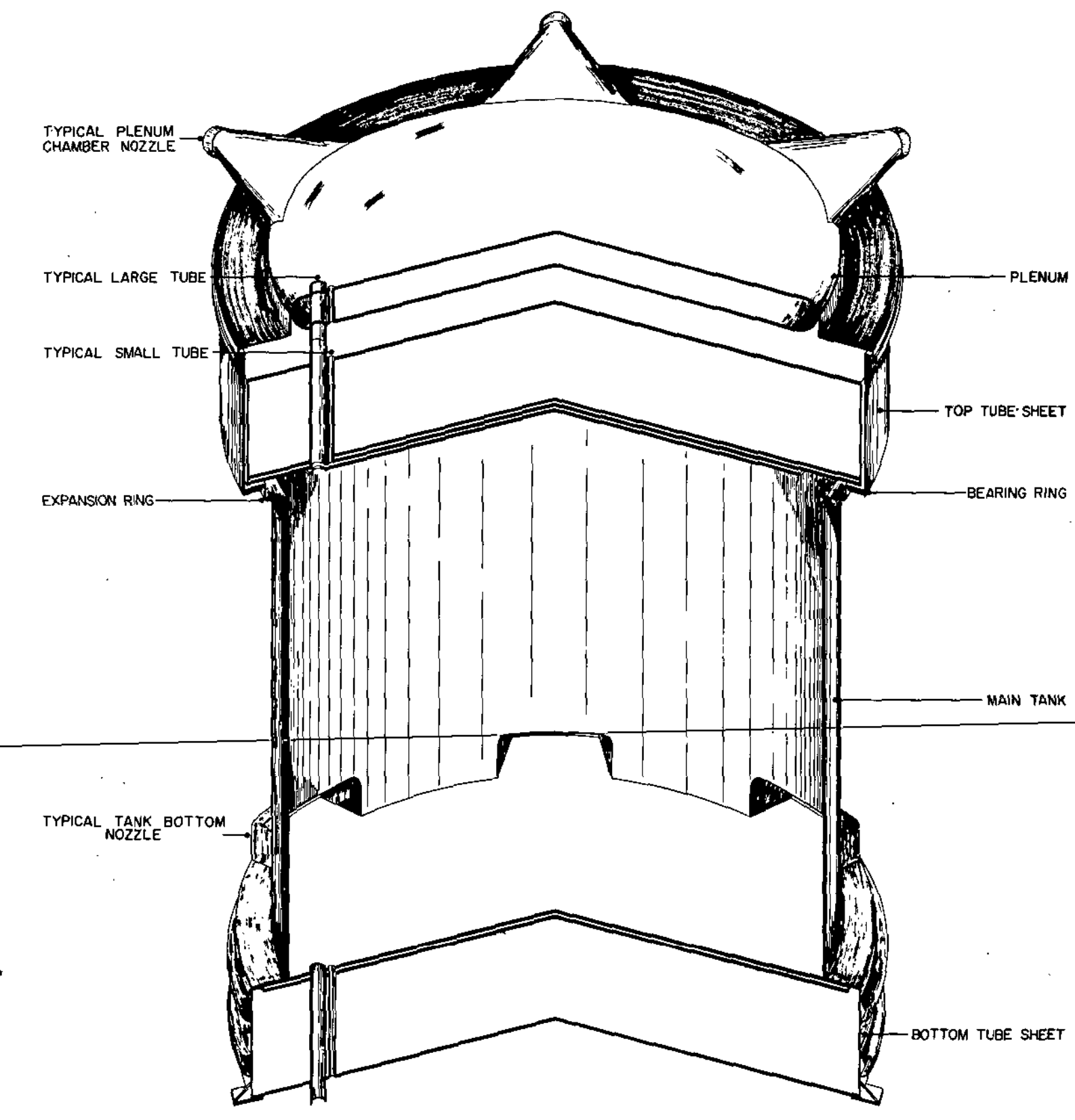

STRUCTURE OF SAVANNAH RIVER REACTOR 
FIGURE 2

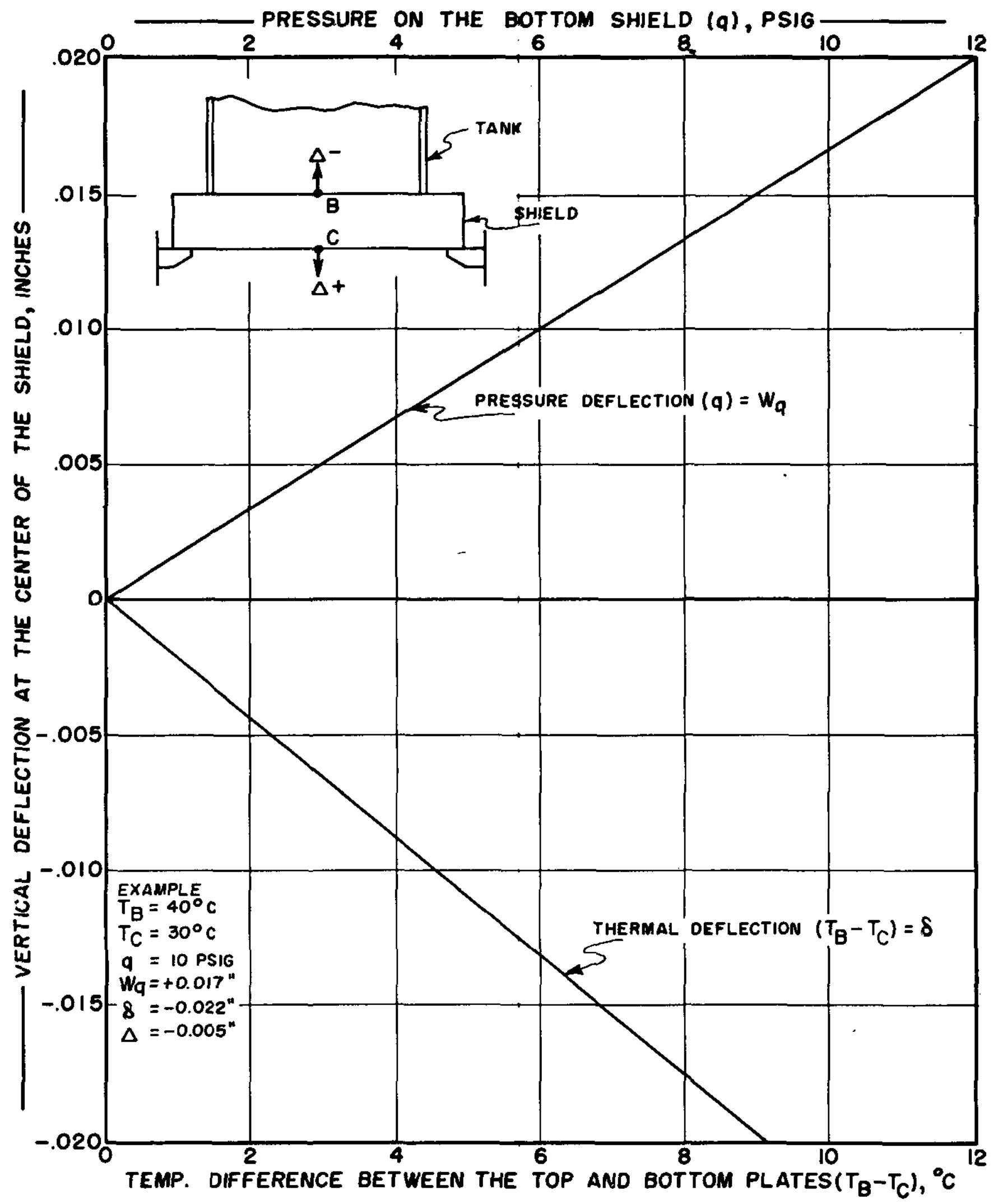

DEFLECTION OF THE BOTTOM SHIELD 


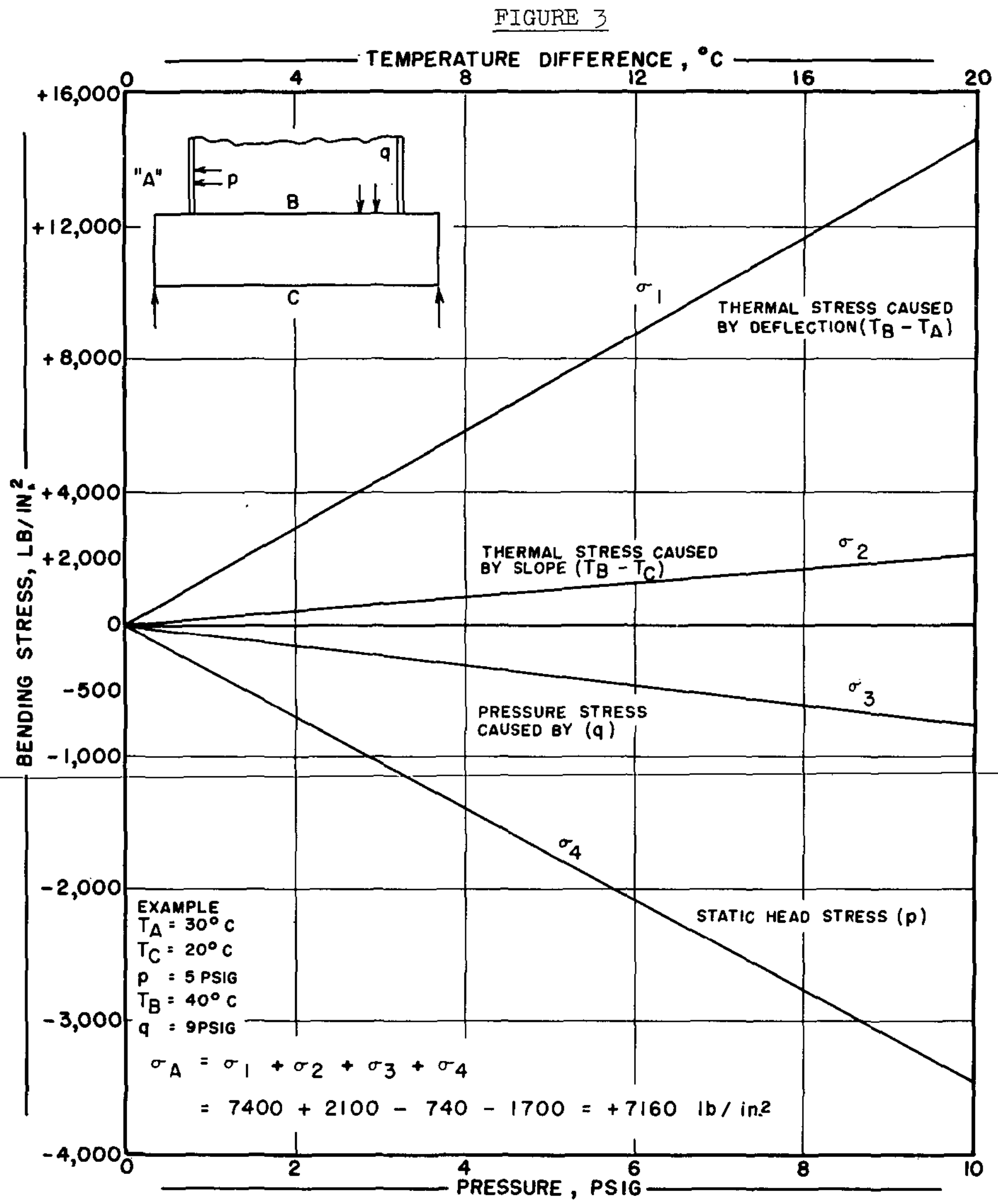

BENDING STRESS IN THE TANK WALL AT "A" 


\section{SOLUTION OF EQUATION 13}

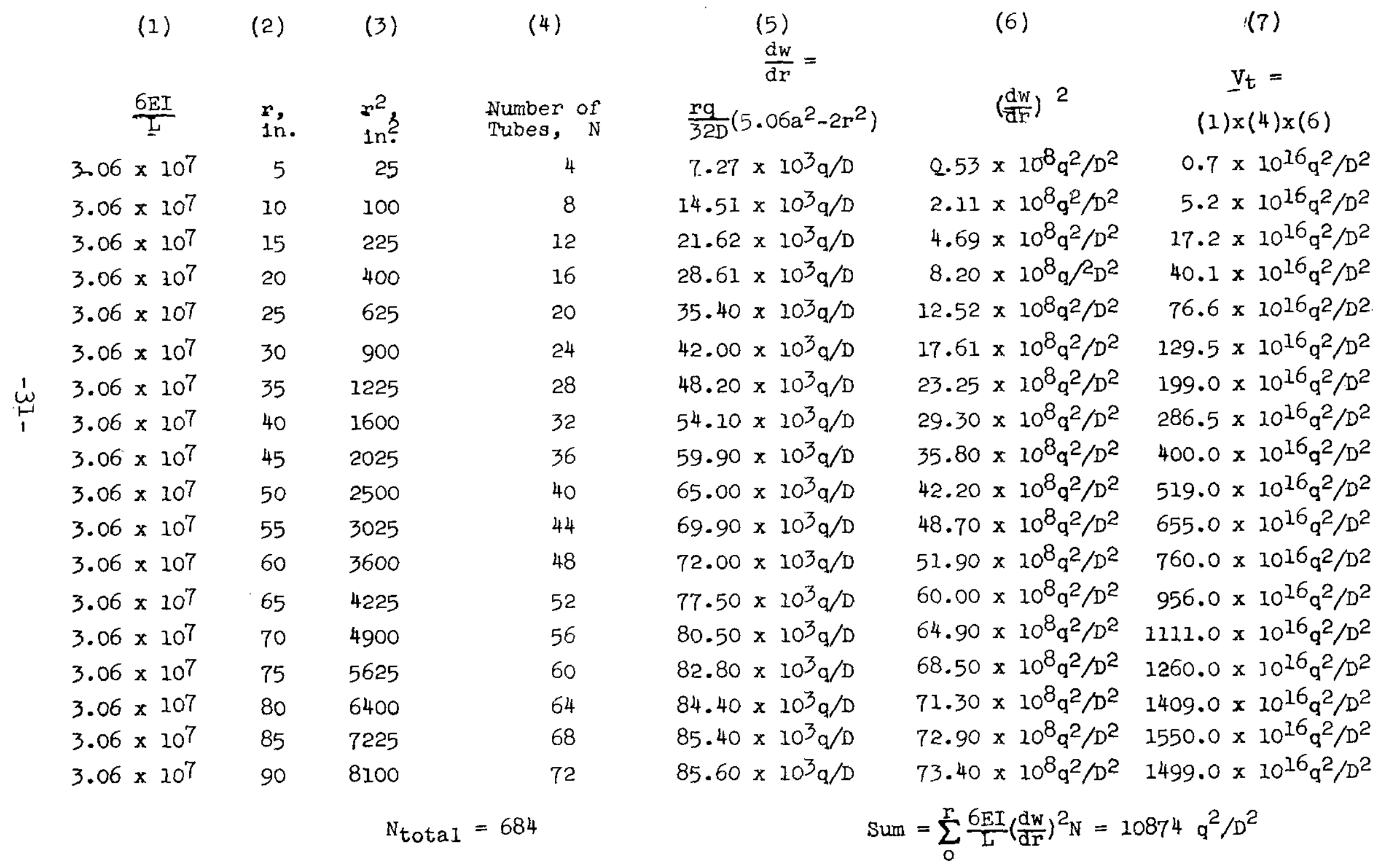




\section{INTERNAL DISTRIBUTION}

No. of Copies
(5) $\mathrm{AEC}, \mathrm{SROO}$
Aiken; S. C.
(1) $\begin{aligned} & \text { R. M. Evans - B. H. Mackey } \\ & \text { H. Worthington } \\ & \text { J. E. Cole - M. H. Smith - } \\ & \text { J. B. Tinker }\end{aligned}$
Wilmington AED
(1) ${ }^{\mathrm{D}}$ " $\mathrm{F}$ " Babcock
(1) S. I. Winde
Englneering Department
(1) H. L. Greene
: Savannah River Plant
(1) W. P. Overbeck
(1) A. A. Johnson
I P.A. Dahlen
(1) PRD File
11
II
(1) M. H. WahI - C. W. J. Wende Savannah River Laboratory
I J. T. Carleton
(1) R. R. Hood
(1) J. W. Walker
(15) TIS File
(1) TIS File Record Copy

11
11
$n$
11




\section{RECORD COPY CHECK LIST}

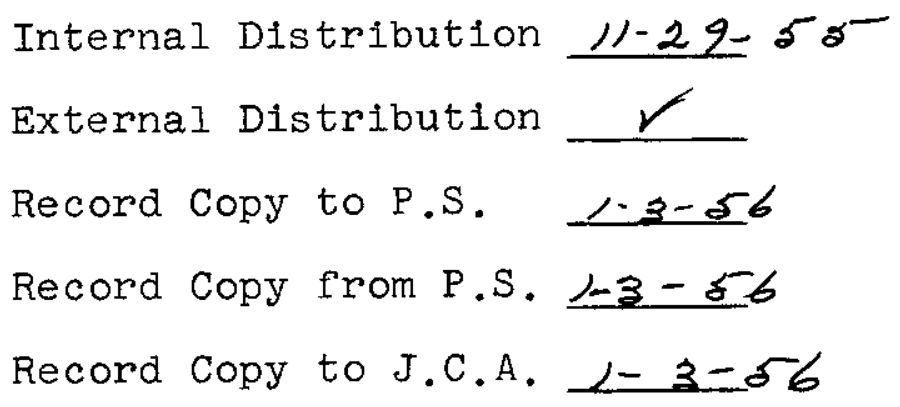

The following 1tems are to be bound with the Record Copy:

\section{Secret Confidential Unclassified}

Approval Sheet

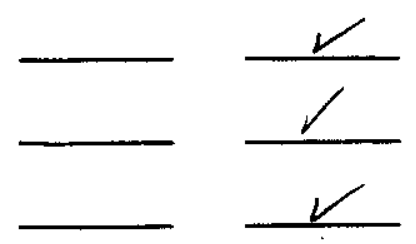

External Distribution

(M-3679) (TID-4500)

Publication Form

AEC Approval 


\section{Exthed Pritustiv \\ \% \\ $12-19-55$}

\section{REACTORS-PRODUCTION}

No. of Copies

\begin{tabular}{c}
11 \\
1 \\
1 \\
5 \\
1 \\
2 \\
1 \\
1 \\
6 \\
1 \\
-4 \\
$1-$ \\
4 \\
1 \\
2 \\
2 \\
1 \\
1 \\
2 \\
1 \\
4 \\
1 \\
1 \\
2 \\
2 \\
65 \\
\hline 124 \\
150 \\
\hline 244 \\
$4 / 9$
\end{tabular}

\section{Standard Dist ribution}

Argonne National Laboratory

Armed Forces Special Weapons Project (Sandia)

Armed Forces Special Weapons project, Washington

Atomic Energy Commission, Washington

Battelle Memorial Institute

Bettis Plant (WAPD)

Brookhaven National Laboratory

Bureau of Ships

Carbide and Carbon Chemicals Company (ORNL)

Chicago Patent Group

-dupont-Gompany,-Augustz-.

duPont-Gompany, Wilimington-

General Electric Company, Richland

Hanford Operations Office

Knolls Atomic Pover Laboratory

Los Alamos Scientific Laboratory

Massachusetts Institute of Technology (Benedict)

New York Operations Office

North American Aviation, Inc.

Patent Branch, Washington

Phillips Petroleum Company (NRTS)

San Francisco Operations office

USAF Headquarters

University of California Radiation Laboratory, Berkeley

University of California Radiation Laboratory, Livermore

Technical Information Service, Oak Ridge

Technical Information Service, Oak Ridge

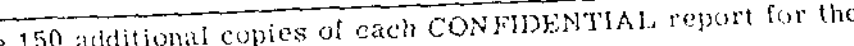


TO:

Print Shop

Due Date: 12/13/55

FROM: Editing Group

The documents listed on the reverse side are authorized for external distribution as of this date, providing the following changes are made.

Bind and issue 434 copies for External Arstrubution without distribution page.

$$
\begin{aligned}
& \text { T/S File } \\
& \text { M-3679 } \\
& \frac{0}{4} \text { AEC, OakRidg }
\end{aligned}
$$

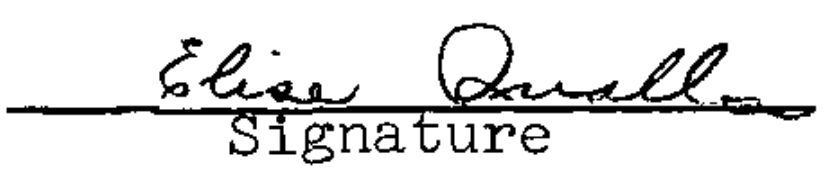

This form to be transmitted to the Document Section with documents. File Record Copy with Approval Shat distribution Page, and job Sheet 
TO: Editing Group, A-148, 773-A

FROM: Document Section

Date: 11-29-5T?

The following documents were circulated internally on this date.

$$
D P-133 \quad C . N . D
$$

$$
\text { JUS. E. }
$$


Report Number DP-133

Author

Walker, John W.

Title Dtien Amatipin of the SRF Teacter Tonk

Stresses In A Tank Supported By A Header

category Reacters, Production

sunrien

Classification $\Leftrightarrow$ Confiantid

Distribution

Manuscript Approval

Reproduction Copy Approval

Final Copy Approval

Recommended for P'xblication......
Author

Div. Head Sec. Dir. Lab. Dir.h

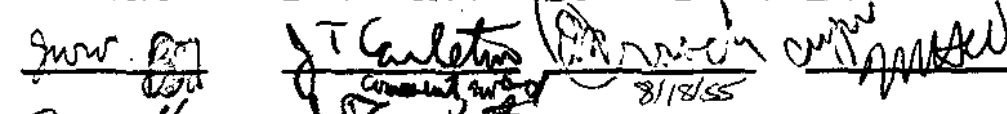

Required

..... Optional

TO BE FILLED OUT BY TIS

MS:pp. Typed _ 32 Figures__ 3 Tables _ _ TotaI pp.

Direct Master Photo Offset $\_$Carbon Ribbon Fabric

Paper Stock offset $70^{*}$ Cover

No: Copies: Internal 38 Int. Extra 28 TID-4500 M-3679 Other (oakpia) 300 Total Copies 462 FD:pp. Typed 27 Figures 3 Tables 1 Total pp. 31 ; Doc. Date October1955 Received Int. Issue Ext. Issue

Remarks File Poend ropu $=1$ with bist peos Reqular Internel; 32 ," SROO.AEC $-5 \quad .1$ TIS FiTe
Ext. $M-3679-119$
$A E C$ Ertua AECRidge - 300$\}$ 
$D P-133$ S C U Titie

Author

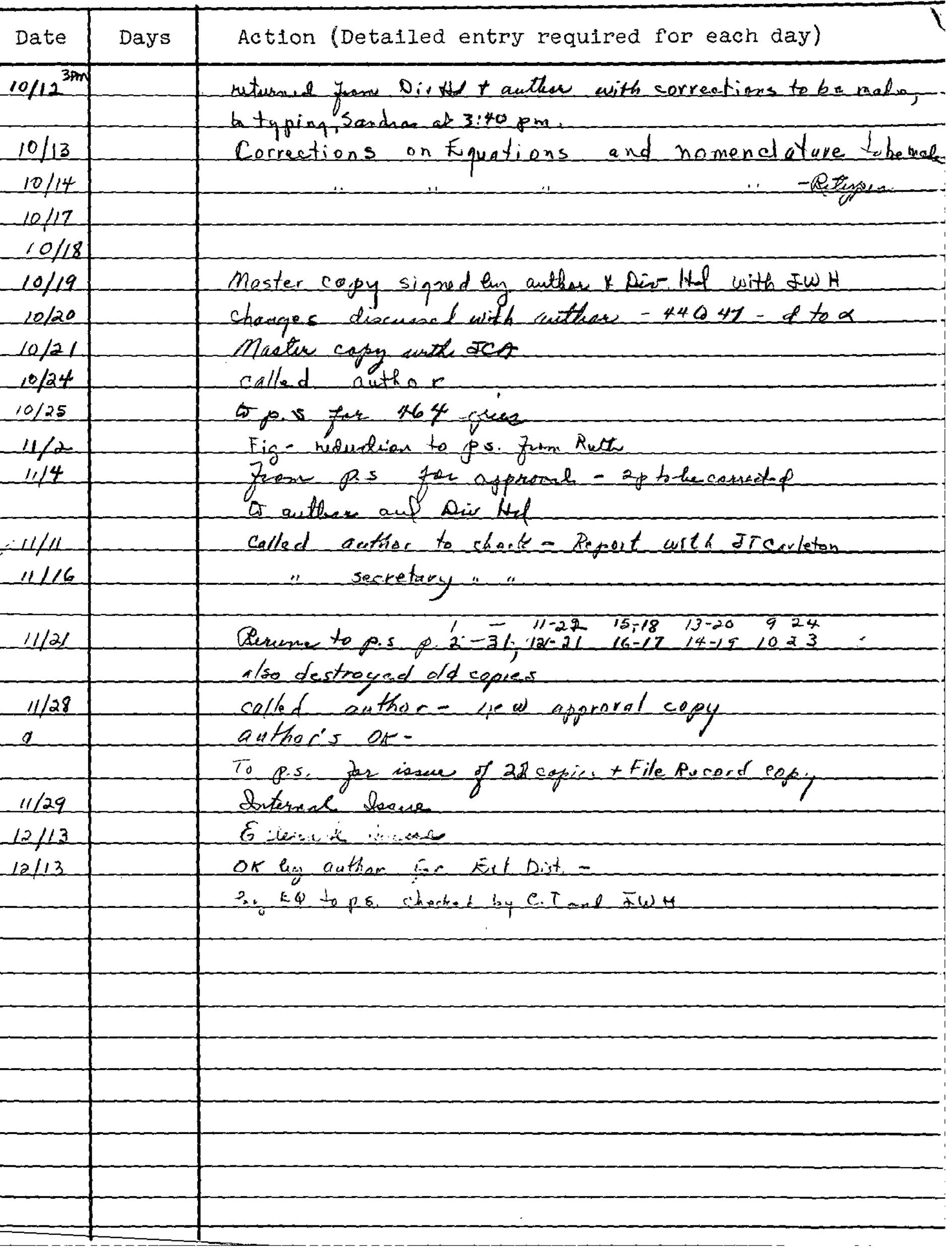


